\title{
WINGS OF THE MOURNING CLOAK BUTTERFLY SNIPPED BY ANT
}

\section{By Arthur Loveridge}

When passing the stump of a silver birch at noon, I noticed that it was oozing sap from two spots where poles had been cut recently. On each was a Mourning Cloak Butterfly (Euvanessa antiopa). One was drinking the sap quietly, the other moved about restlessly and continually flapped its wings. Approaching closer I saw that several ants (subsequently identified for me by Dr. W. M. Wheeler as Camponotus herculeanus ligniperda var. noveboracensis Fitch) were running about and around the butterfly. One ant in particular seemed to be annoying the butterfly by climbing on its abdomen. This caused the insect to flap its wings violently until the ant decamped. It soon returned and reaching up began biting at the inner posterior edge of the butterfly's hind wings. I now saw for the first time how ragged the wings were at this place, and as I watched, first one and then another piece of wing floated away on the gentle breeze that was blowing. Then I realized that the ant was snipping off pieces. Another ant ran up and touched the butterfly's proboscis, causing the butterfly to draw it up and move about for a time before settling to feed again. Then a wasp (Polistes sp.) alighted near the butterfly and fed up to its very flank. At that the butterfly, without ceasing to feed, flapped its wings down and held them so for a moment. The wasp just crouched flat beneath them until they were raised again, then went on with its own meal. I had an excellent view of its action under the wing as my face was level with the stump and a bare eighteen inches away. Then an ant, hurrying up, seized the wasp by one leg; they rolled over and over until they fell off the stump to the ground a foot below. There they separated and the wasp, in leisurely fashion, crawled up the stump and recommenced feeding. I moved slightly but enough to startle the Mourning Cloak, which must have been about full fed by this time, and she flew off (Newton Centre, May 12, 1935). 

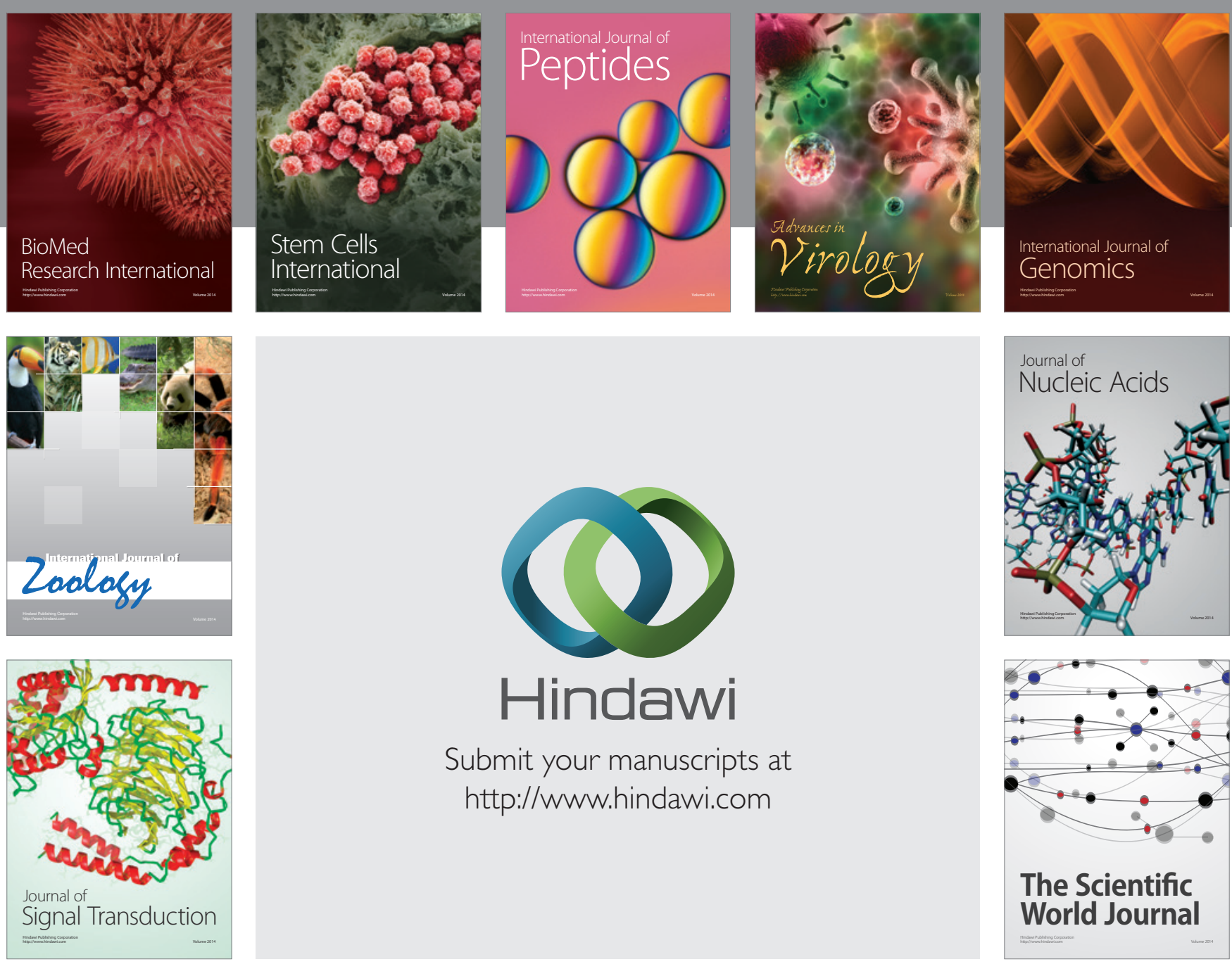

Submit your manuscripts at

http://www.hindawi.com
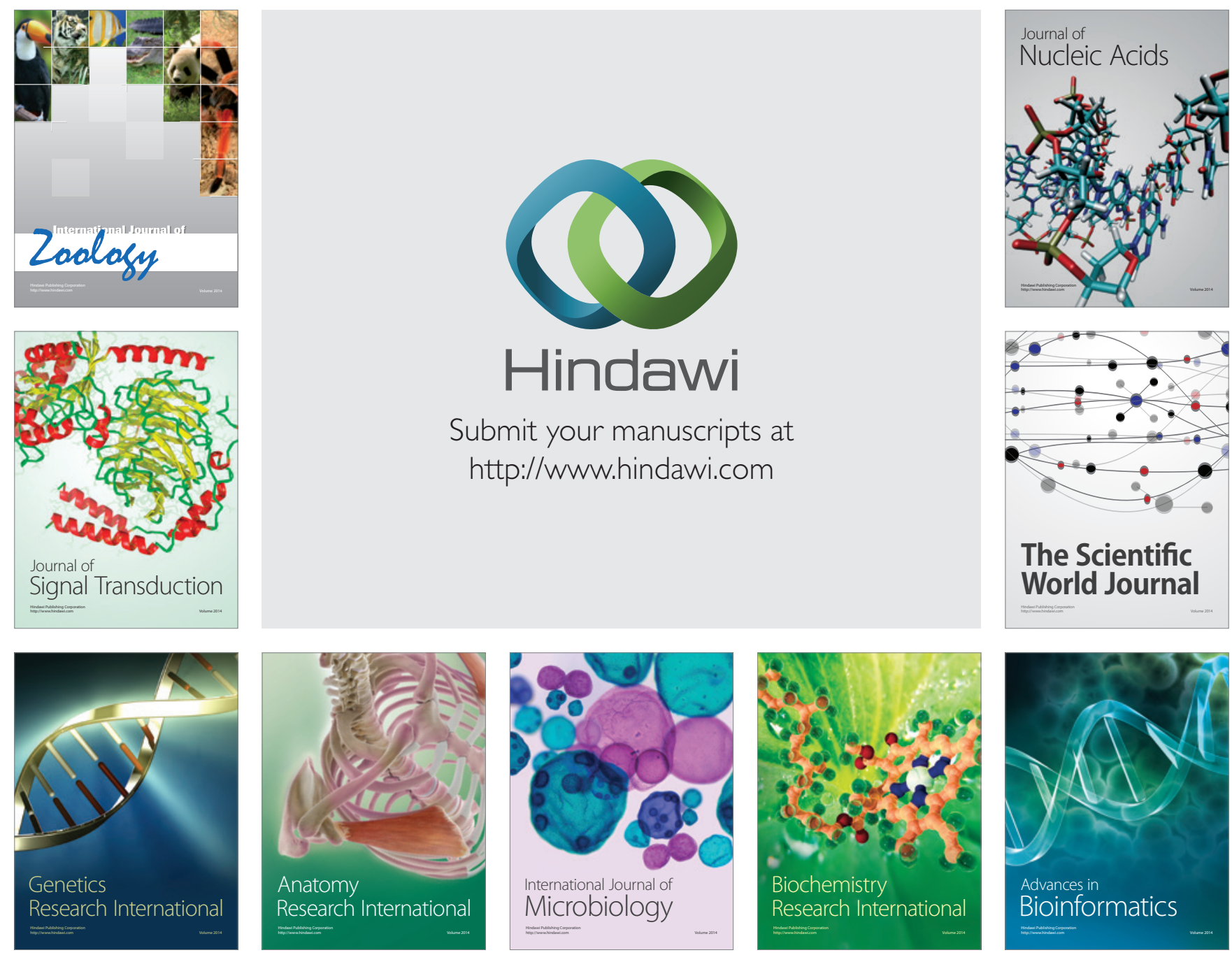

The Scientific World Journal
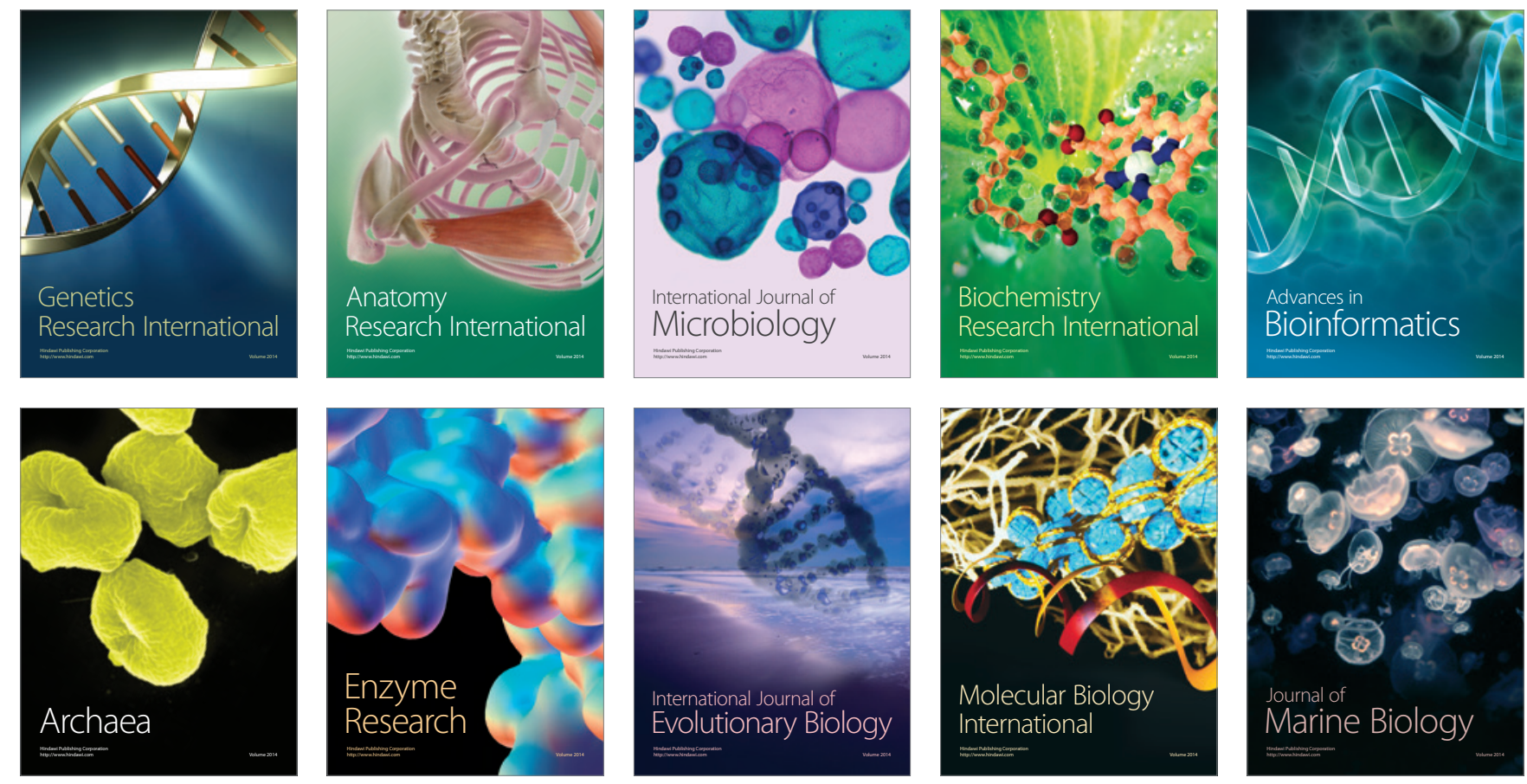